\title{
Sphere-forming cell subsets with cancer stem cell properties in human musculoskeletal sarcomas
}

\author{
MANUELA SALERNO ${ }^{1,3}$, SOFIA AVNET $^{1}$, GLORIA BONUCCELLI $^{1,3}$, ADRIANA ERAMO $^{4}$, \\ RUGGERO DE MARIA $^{5}$, MARCO GAMBAROTTI ${ }^{2}$, GABRIELLA GAMBERI $^{2}$ and NICOLA BALDINI ${ }^{1,3}$
}

\begin{abstract}
Departments of ${ }^{1}$ Orthopaedic Pathophysiology and Regenerative Medicine and ${ }^{2}$ Pathology, Istituto Ortopedico Rizzoli; ${ }^{3}$ Department of Biomedical and Neuromotor Sciences, University of Bologna, Bologna; ${ }^{4}$ Department of Hematology, Oncology and Molecular Medicine, Istituto Superiore di Sanità; ${ }^{5}$ Regina Elena Cancer Institute, Rome, Italy
\end{abstract}

Received January 8, 2013; Accepted March 4, 2013

DOI: $10.3892 /$ ijo.2013.1927

\begin{abstract}
Musculoskeletal sarcomas are aggressive malignancies often characterized by an adverse prognosis despite the use of intense multiagent chemotherapy or molecular targeted therapy in combination to surgery and radiotherapy. Stem-like cells identified within solid tumors have been recently implicated in drug resistance, metastasis and local relapse. Here, we report the identification of putative cancer stem cells (CSCs) in sarcomas using a sphere culture system. These sarcospheres, able to grow in anchorage-independent and serum-starved conditions, express the pluripotent embryonic stem cell marker genes OCT3/4, Nanog and SOX2. Expression levels of these genes were greater in sarcospheres than in the parental tumor cultures. Importantly, the isolated tumor spheres transplanted into mice were tumorigenic and capable of recapitulating the human disease. Finally, we demonstrated that low $(1 \%) \mathrm{O}_{2}$ conditions, reproducing those found within the tumor microenvironment, significantly increase the number and the size of sarcospheres. The sphere formation assay is, therefore, a valuable method for the isolation of putative CSCs from human sarcomas and its efficiency is improved by controlling oxygen availability. This method provides a reliable preclinical model that can be used for future studies aimed at investigating crucial aspects of sarcoma biology, such as resistance to treatments and relapse.
\end{abstract}

\section{Introduction}

Musculoskeletal sarcomas are relatively rare malignancies of bone and soft tissues with unknown etiology, ill-defined pathogenesis and rapid progression. Sarcomas are indeed highly aggressive tumors and induce devastating consequences both

Correspondence to: Dr Manuela Salerno, Department of Orthopaedic Pathophysiology and Regenerative Medicine, Istituto Ortopedico Rizzoli, Via di Barbiano 1/10, I-40136 Bologna, Italy E-mail: manuela.salerno@ior.it

Key words: sarcoma, cancer stem cells, sarcosphere, hypoxia in terms of morbidity and mortality $(1,2)$. The life expectancy of sarcoma patients has not significantly changed over the past 30 years despite the use of non-specific aggressive multidrug chemotherapy regimens in addition to surgery and/or radiation therapy and the recent adoption of biological approaches based on the identification of molecular targets has not remarkably modified the outcome (3). It is likely that current preclinical models are insufficient to describe the complexity of sarcomagenesis and, accordingly, to identify effective targets for therapy.

Over the last decades, the discovery of a tumor-initiating cell population in human acute myeloid leukemia $(4,5)$ has led to the introduction of the cancer stem cell (CSC) concept instead of the classical stochastic model to describe tumor development. This hypothesis postulates that cancers, like normal adult tissues, contain a minority of quiescent uncommitted cells that reside at the apex of the neoplastic cell hierarchy and originate from deregulated endogenous stem cells or an aberrant reprogramming of committed cells (6). According to this hypothesis, CSCs drive cancer development as well as its progression, response to therapy, and metastatization (7). The pioneering works on leukemia stem cells prompted further research into a wide variety of solid malignancies, including breast, brain, colon, pancreas, melanoma, ovary and prostate cancers, where CSCs have been identified and characterized (8-14). The isolation assay for CSCs is based on their ability to grow forming suspended spherical, clonal colonies. To date, this sphere-forming assay is still the most widely used method $(8,10,15-17)$. The capacity to grow as floating spheres has also been exploited for the isolation of putative CSCs from sarcomas. In particular, sphere cultures from sarcomas, so-called 'sarcospheres', have been isolated from continuous cell lines $(18-22)$ or tissue samples $(23,24)$ by the sphere assay. Other investigators have used indirect assays, based on detoxification systems that are known to be active in stem cells, like the Hoechst ${ }_{33342}$ dye exclusion test (25) or the aldehyde dehydrogenase 1 (ALDH1) activity (26). Recently, it has been reported that limited oxygen availability, reproducing the physiological tumor microenvironment, increase the CSCs fraction and promote a more undifferentiated state (27). Therefore, the control of the culture condition could be a crucial aspect for the isolation of CSCs. Here, starting from 
a number of fresh tissue samples, we verified the efficacy of the sphere system assay to isolate sphere cultures from human sarcomas and analysed the stem cell-related properties of the resulting cultures in terms of gene expression and in vivo tumorigenic potential. We then exposed sarcospheres to a hypoxic environment $\left(1 \% \mathrm{O}_{2}\right)$, and compared their behaviour to that of cells grown at $21 \% \mathrm{O}_{2}$.

\section{Materials and methods}

Sample collection and sphere system assay. Fresh biopsies from 49 patients (25 males and 24 females, age 6-85 years) with a histological diagnosis of sarcoma were prospectically obtained between 2009 and 2012. All samples were collected after a signed informed consent and following the institutional ethics committee approval. Tumor and patient data are summarized in Table I. Samples were subjected to mechanical and enzymatic digestion to obtain single cell suspensions. Cells were maintained at $37^{\circ} \mathrm{C}$ in a humidified $5 \% \mathrm{CO}_{2}$ atmosphere in DMEM:F12 medium with progesterone (20 nM), putresceine $(10 \mu \mathrm{g} / \mathrm{ml})$, sodium selenite $(30 \mathrm{nM})$, apo-transferrin $(100 \mu \mathrm{g} / \mathrm{ml})$, and insulin $(25 \mu \mathrm{g} / \mathrm{ml})$ (Sigma-Aldrich, St. Louis, MO) in low-attachment flasks (Nunc, Penfield, NY). Fresh human EGF (20 ng/ml) and bFGF (10 ng/ml) (PeproTech, Rocky Hill, NJ) were added twice a week until cells started to grow forming floating aggregates. Cultures were expanded by mechanical dissociation of spheres, followed by re-plating of cells and residual cell aggregates in complete medium.

Cell lines. In order to obtain parental tumor cell cultures, single cells obtained from biopsies after enzymatic dissociation were seeded in Iscove's modified Dulbecco's medium (IMDM, Invitrogen, Carlsbad, CA), plus $20 \mathrm{U} / \mathrm{ml}$ penicillin, $100 \mathrm{mg}$ / $\mathrm{ml}$ streptomycin and $10 \%$ fetal bovine serum (FBS). The embryonic carcinoma cell line NT2/D1 was purchased from American Type Culture Collection (ATCC, Manassas, VA) and cultured in DMEM/high glucose (Euroclone, Milan, Italy) plus $10 \%$ FBS (Hyclone, Logan, UT). Cells were incubated at $37^{\circ} \mathrm{C}$ in a humidified $5 \% \mathrm{CO}_{2}$ atmosphere. For the hypoxia experiments, the RD rhabdomyosarcoma (RMS) cell line was purchased from ATCC.

Real-time PCR. Total RNA was extracted from sarcospheres by using the NucleoSpin RNA II (Qiagen GmbH, Hilden, Germany), and reverse transcribed. The expression of mRNA for OCT3/4, Nanog, and SOX2 was evaluated using a Light Cycler instrument (Roche Diagnostics, Indianapolis, IN) and the Universal Probe Library (Roche Applied Science). Probes and primers were selected using web-based assay design software (ProbeFinder http://www.rocheapplied-science.com). Sequences and primers are reported in Table II. The results were normalized to GADPH or $\beta$-actin according to the $2^{-\Delta \Delta C T}$ method (28).

Generation and validation of sarcosphere-derived xenografts. Animal experiments were approved by the Service for Biotechnology and Animal Welfare of the Istituto Superiore di Sanità in Rome, Italy and authorized by the Italian Ministry of Health (Decree no. 217/2010-B). To evaluate the in vivo tumorigenesis, sarcospheres were dissociated into single
Table I. Tumor and patient characteristics.

\begin{tabular}{|c|c|c|c|}
\hline $\begin{array}{l}\text { Tumor } \\
\text { histotype }\end{array}$ & $\begin{array}{l}\text { Case } \\
\text { nos. }\end{array}$ & Gender & $\begin{array}{l}\text { Age } \\
\text { range }\end{array}$ \\
\hline Osteosarcoma & $1-11$ & Female $(n=6)$ & $8-71$ \\
\hline$(\mathrm{OS})(\mathrm{n}=11)$ & & Male $(n=5)$ & $13-71$ \\
\hline Chondrosarcoma & $12-20$ & Female $(n=6)$ & $40-78$ \\
\hline$(\mathrm{CS})(\mathrm{n}=9)$ & & Male $(n=3)$ & $25-77$ \\
\hline $\begin{array}{l}\text { Ewing's sarcoma } \\
(\mathrm{ES})(\mathrm{n}=2)\end{array}$ & $21-22$ & Male $(n=2)$ & $55-58$ \\
\hline Liposarcoma & $23-40$ & Female $(n=10)$ & $17-83$ \\
\hline$(\mathrm{LS})(\mathrm{n}=18)$ & & Male $(n=8)$ & $40-76$ \\
\hline Rhabdomyosarcoma & $41-42$ & Female $(n=1)$ & 6 \\
\hline$(\mathrm{RMS})(\mathrm{n}=2)$ & & Male $(n=1)$ & 10 \\
\hline \multirow[t]{2}{*}{ Other $(n=7)$} & $43-49$ & Female $(\mathrm{n}=1)$ & 30 \\
\hline & & Male $(n=6)$ & $51-85$ \\
\hline
\end{tabular}

cells, mixed with an equal volume of growth factor-containing Matrigel (BD Bioscience, Franklin Lakes, NJ) and then $5 \times 10^{4}$ cells were injected in the flank of 4-6-week-old female NOG mice (Charles River Laboratories, Wilmington, MA). When tumor diameter reached a maximum of $10 \mathrm{~mm}$, mice were sacrificed and the tumor tissue was then collected for further investigation.

Xenograft analysis. Hematoxylin and eosin (H\&E) staining was performed to analyse xenograft morphology in comparison to the original tumors. Immunohistochemistry (IHC) was carried out on paraffin-embedded sections to analyse the expression of desmin, myogenin and muscle actin. Primary antibodies anti-desmin (cat. no. D33), anti-myogenin (cat. no. F5D) and anti-muscle actin (cat. no. HHF35) were from Dako (Dako Denmark A/S, Glostrup, Denmark). The presence of the RMS-specific fusion transcript PAX3-FKHR was evaluated by conventional PCR (Invitrogen). Briefly, RNA was extracted from fresh biopsies using a modified method including TRIzol reagent (Invitrogen) and the RNeasy Mini kit (Qiagen $\mathrm{GmbH}$ ) and reverse transcribed. The positive case control consisted of alveolar RMS, which was analysed by sequencing to confirm the specific translocations. Forward and reverse primers were: 5'-CCGACAGCAGCTCTGCCTAC-3', 5'-TGAACTTGCTGTGTAGGGACAG-3'. The PCR products were resolved on $3 \%$ agarose gel electrophoresis followed by Gel Star staining (Lonza, Rockland, ME). The sequencing was performed by Bio-Fab Research (http://www.biofabresearch. it/index 2.html, Rome, Italy). Computer analysis of sequences was performed by basic local alignment search tool (BLAST) sequence similarity searches using the National Center of Biotechnology Information Database (NCBI).

Hypoxia induction. The RD cell line was maintained as monolayer in complete IMDM. To obtain sarcospheres, RD 
Table II. Sequences and primers used for real-time PCR.

\begin{tabular}{llll}
\hline Gene & Accession no. & \multicolumn{1}{c}{ Forward primer } & Reverse primer \\
\hline OCT3/4 & NM_002701.4 & CTTCGCAAGCCCTCATTTC & GAGAAGGCGAAATCCGAAG \\
Nanog & NM_024865.2 & ATGCCTCACACGGAGACTGT & AGGGCTGTCCTGAATAAGCA \\
SOX2 & NM_003106.3 & GGGGGAATGGACCTTGTATAG & GCAAAGCTCCTACCGTACCA \\
GADPH & NM_002046.3 & AGCCACATCGCTCAGACAC & GCCCAATACGACCAAATCC \\
$\beta$-actin & NM_001101.2 & CCAACCGCGAGAAGATGA & CCAGAGGCGTACAGGGATAG \\
\hline
\end{tabular}

Table III. Established sarcosphere cultures from human sarcomas.

\begin{tabular}{|c|c|c|c|c|}
\hline Case no. & Diagnosis & Patient sex/age & Site & $\begin{array}{c}\text { Time for sphere } \\
\text { formation (weeks) }\end{array}$ \\
\hline 7 & Osteosarcoma, relapse & $\mathrm{M} / 57$ & Ilium & 3 \\
\hline 13 & Chondrosarcoma & $\mathrm{F} / 68$ & Acetabulum & 16 \\
\hline 22 & Extraskeletal Ewing's sarcoma pPNET & $\mathrm{M} / 55$ & Thigh & 2 \\
\hline 40 & Liposarcoma & $\mathrm{M} / 53$ & Thigh & 8 \\
\hline 41 & Alveolar rhabdomyosarcoma, relapse & $\mathrm{F} / 6$ & Thigh & 2 \\
\hline
\end{tabular}

were then cultured in anchorage-independent condition as previously described, until the formation of floating spheres, indicated as RDsph. Hypoxic atmosphere $\left(1 \% \mathrm{O}_{2}\right)$ condition was created by using a modular incubator chamber (BillupsRothenberg, Inc., Del Mar, CA).

Sphere characteristics under hypoxia. To evaluate the sphere formation efficiency, single cells derived from RDsph were seeded at 500 cells/well in low attachment 6-well plates at 21 and $1 \% \mathrm{O}_{2}$. After 10 days, the total number of spheres was manually counted. To analyse the sphere proliferation and size, and the expression of stem cell-related genes, cells derived from RDsph were seeded in low attachment 6-well plates $(20,000$ cells $/ \mathrm{ml})$ and incubated at 21 and $1 \% \mathrm{O}_{2}$ for 10 days. Cell growth was evaluated at 3 and 10 days by a dye exclusion viability assay. The radius of each tumor spheroid was measured using NIS-Elements Microscope Imaging Software (Nikon, Tokyo, Japan) and used to calculate the volume $\left(V=4 / 3 \pi r^{3}\right)$. Real-time PCR, as previously described, evaluated the expression of OCT3/4, Nanog and SOX2 at 21 or $1 \% \mathrm{O}_{2}$.

Statistical analysis. Due to the small number of observations, data were considered as not normally distributed, and the nonparametric Mann-Whitney U test was used and $\mathrm{p}<0.05$ was considered significant. Statistical analysis was performed with the StatView ${ }^{\mathrm{TM}}$ 5.0.1 software (SAS Institute Inc., Cary, NC). Values were expressed as means \pm SEM.

\section{Results}

Establishment of sarcosphere cultures from human sarcomas. Using a sphere-forming assay, we established sphere cultures

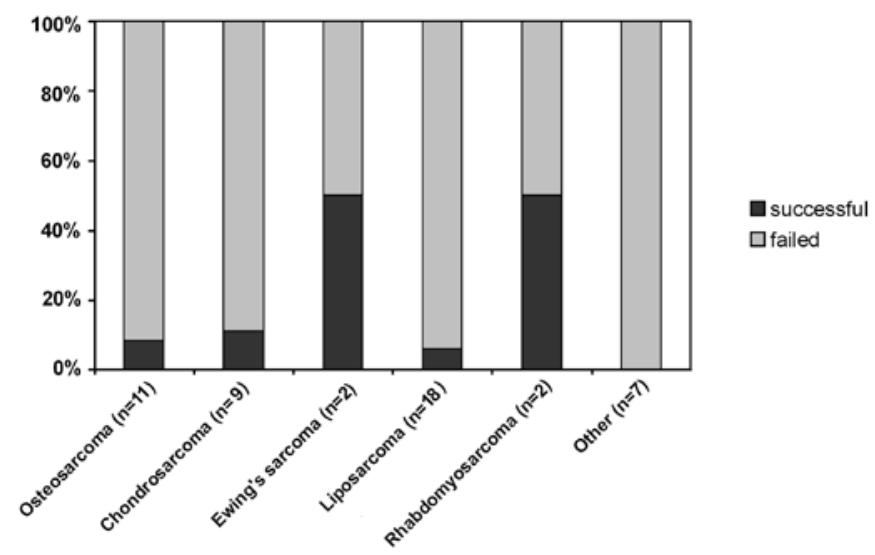

Figure 1. Isolation efficiency of sarcosphere cultures from 49 fresh human sarcomas. The efficiency yields were $9 \%$ for osteosarcoma (OS), $11 \%$ for CS, $6 \%$ for liposarcoma (LS), and $50 \%$ for RMS and ES.

in 5 out of 49 cases (10.2\%) (Fig. 1). Details of tumor histotypes, diagnosis and time needed for sphere formation are summarized in Table III. Established cultures consisted in floating cell aggregates (Fig. 2A). We also obtained parental tumor cell cultures from Ewing's sarcoma (ES) and RMS samples (cases 22 and 41; Fig. 2B).

Expression of stem cell-associated genes in sarcospheres. To assess stem cell-related properties, we analysed the expression of OCT3/4, Nanog and SOX2 by real-time PCR. The pluripotent embryonal cell line NT2/D1 was used as a positive control. All sarcosphere cultures expressed consistent mRNA levels for OCT3/4, Nanog and SOX2, which were significantly higher than that of the positive control (cases 22 and 40). When 
A

case 7

case 13
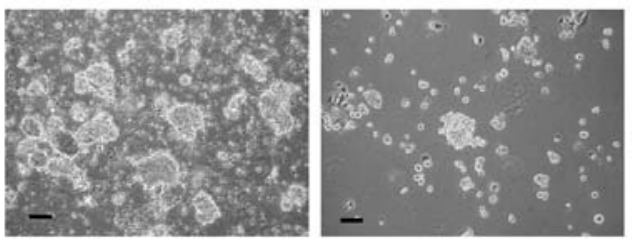

case 22

case 40

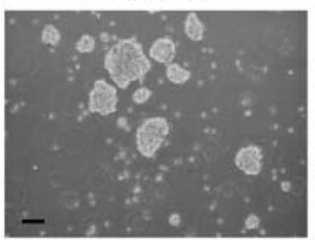

case 41

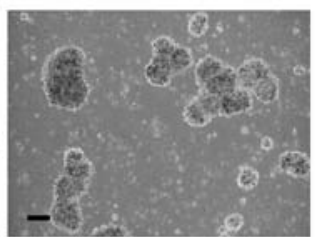

(i)

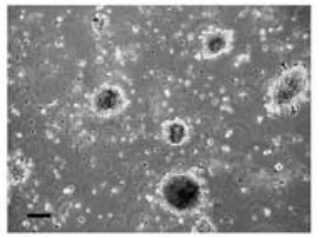

$\mathrm{B}$

case 22

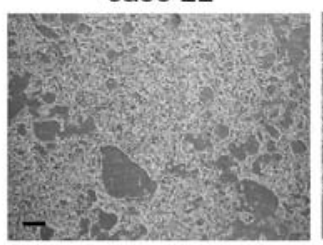

case 41

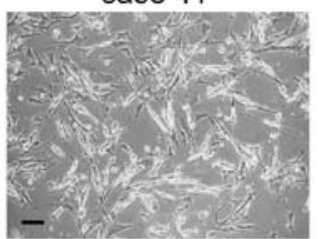

Figure 2. Morphology of sarcospheres obtained from fresh biopsies through the sphere assay. (A) Spheres from OS (case 7), CS (case 13), ES (case 22), LS (case 40) and RMS (case 41). Representative images. (B) Adherent tumor cells obtained from cases 22 and 41, representative images. Scale bar, $100 \mu \mathrm{m}$.
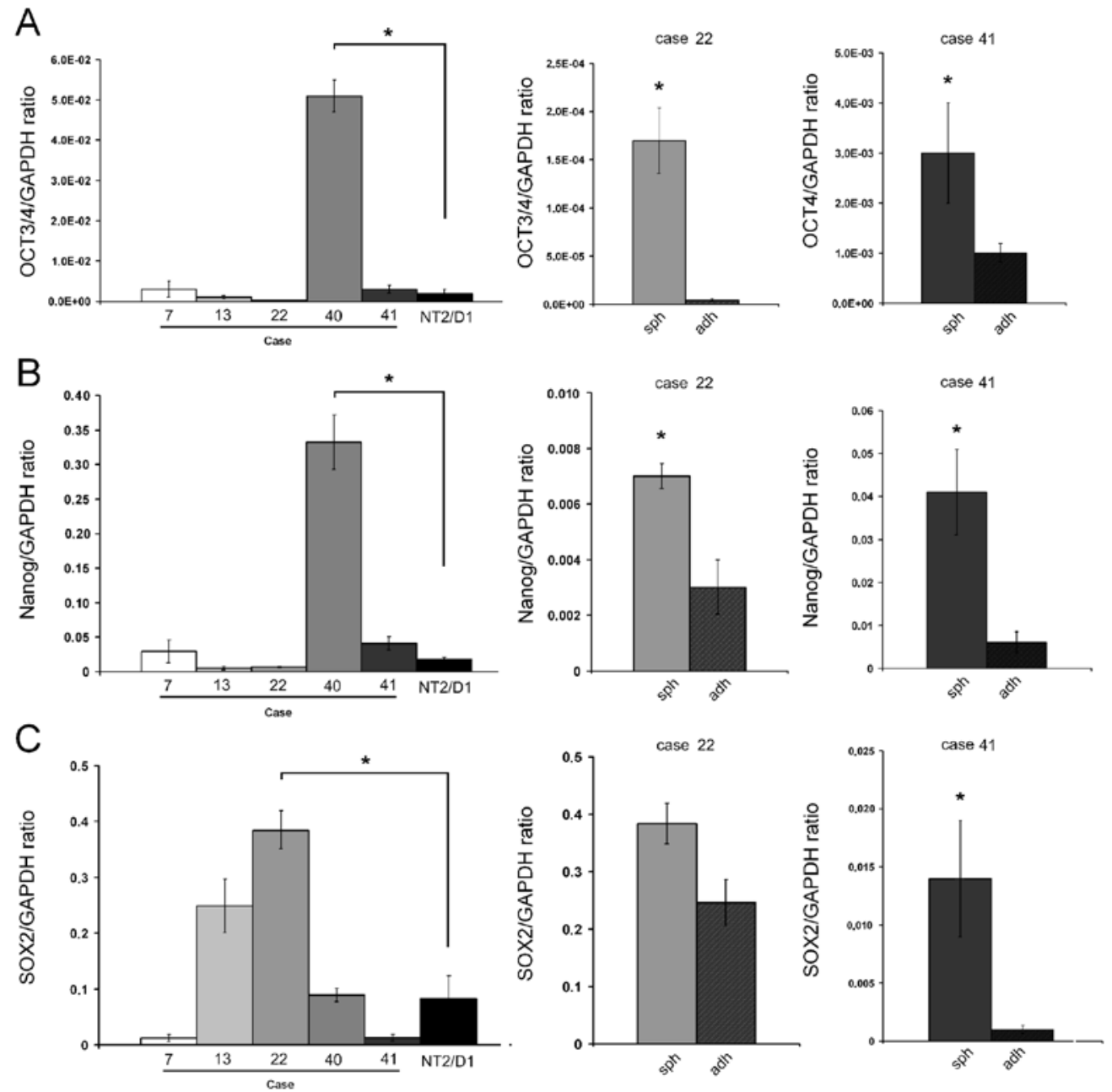

Figure 3. Gene expression of the stem cell markers. (A) OCT3/4, (B) Nanog and (C) SOX2 evaluated in primary sarcospheres in comparison to NT2/D1 cells or parental tumor cells $(a d h)$ by real-time PCR. The levels of these markers in the spheres were comparable or higher than the control. In addition, note the higher gene expression in sarcospheres from cases 22 and $41(s p h)$ compared to $a d h$. Normalization with GAPDH. $\mathrm{p}=0.034, \mathrm{n}=3$. 


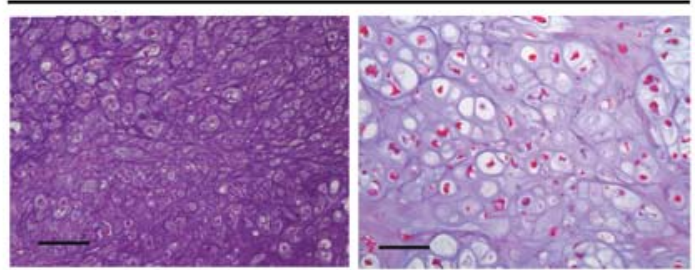

B

case 41

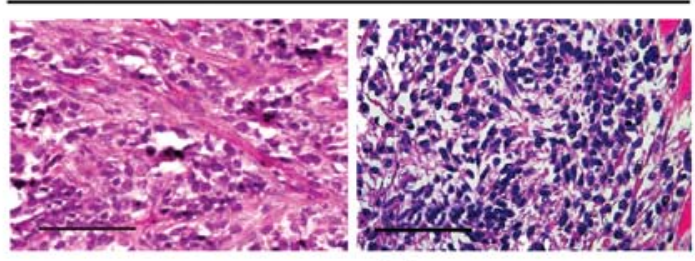

C

case 41

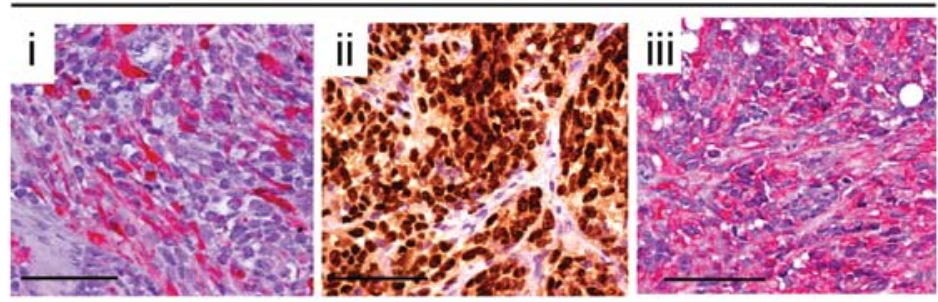

D

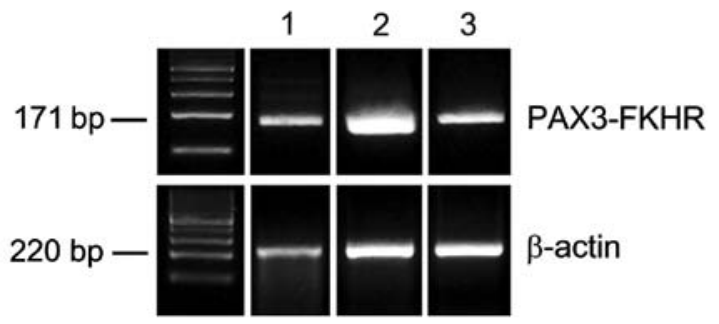

Figure 4. Xenograft analysis. (A and B) H\&E staining of tumor specimens derived from injection of spheres from CS (case 13, left panel) or from RMS (case 41, left panel). Note that xenografts recapitulated the morphology of the patient tumors (cases 13 and 41, right panels). (C) RMS-derived xenograft (case 41) was analysed by IHC for desmin (i), myogenin (ii) and G-actin (iii) to confirm the tumor histology. Scale bar, $100 \mu \mathrm{m}$. (D) Additionally, RT-PCR revealed the PAX3-FKHR transcript in RMS spheres derived from case 41 (lane 1), that was the same found in patient tissue (lane 2). Lane 3, positive control. $\beta$-actin as a reference gene.

compared to adherent parental cells (cases 22 and 41), sarcospheres expressed significantly higher levels of mRNA for all of the examined genes (Fig. 3).

In vivo tumorigenic potential. To provide further evidence that these cells represented a putative CSC population, single cells derived from chondrosarcoma (CS) and RMS sarcospheres (cases 13 and 41) were subcutaneously injected into NOG mice. H\&E staining of xenograft obtained from CSCs of CS (case 13) could be related to a grade 2-3 CS with abundant chondroid matrix and lipid droplets, as observed in the original biopsy (Fig. 4A). H\&E staining for RMS xenograft (case 41) showed small tumor cells with scant cytoplasm and regular nuclei, arranged in clumps outlined by hyalinised fibrous septa, resembling the original tumor pattern (Fig. 4B). Immunostaining of RMS xenograft for desmin, myogenin and muscle-actin also confirmed the original tumor phenotype (Fig. 4C). Moreover, RT-PCR analysis revealed the presence of mRNA transcript for PAX3-FKHR in RMS sarcospheres, the same alteration detected in the original tumor (Fig. 4D).
All products were confirmed by DNA sequencing (data not shown).

Culture under hypoxia. To evaluate if low oxygen levels could be suitable for CSC spheres, we cultured spheroids obtained from RD cell line at $21 \%$ (normoxia) or $1 \% \mathrm{O}_{2}$ (hypoxia). Under hypoxia, the number (Fig. 5A) and volume (Fig. 5B) of RDsph were significantly higher than in normoxia. Hypoxia also led to a significant increase of the growth rate (Fig. 5C). Finally, the expression of mRNA for stemness genes tended to increase under hypoxic conditions compared to normoxia (Fig. 5D).

\section{Discussion}

The identification and characterization of CSCs has led the way to novel perspectives for cancer treatment. In fact, this minority subset of the tumor cell population is putatively responsible for drug resistance, local relapse and metastasis, crucial features of malignancies that directly impact on patient 
A

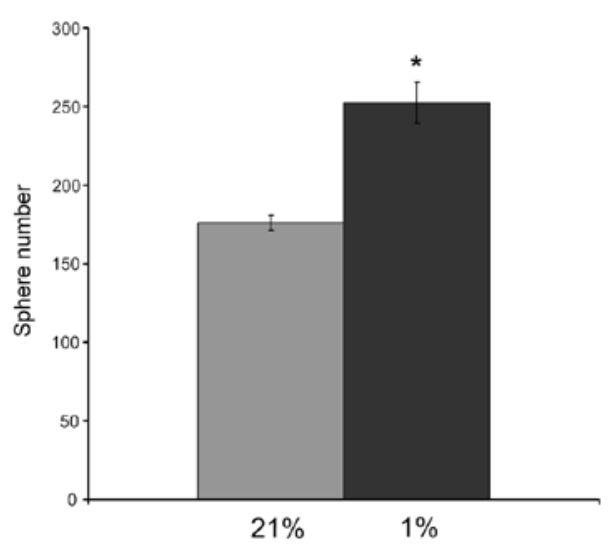

C

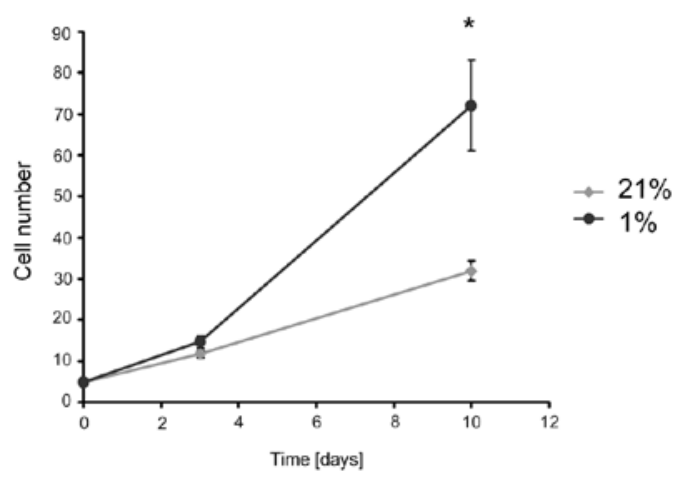

B
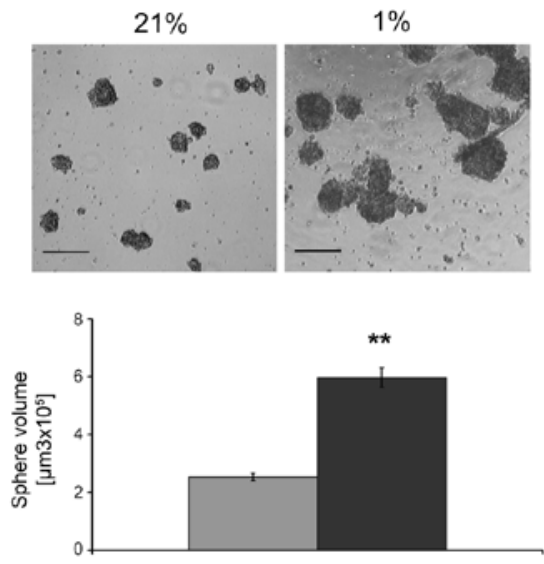

D
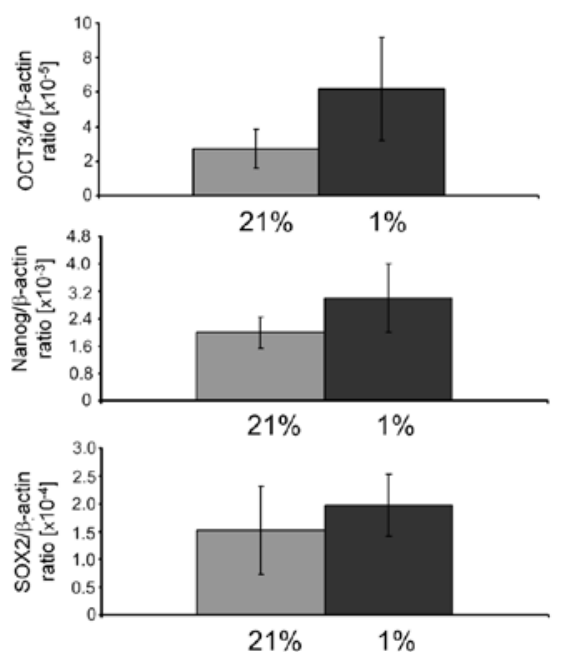

Figure 5. Effects of hypoxia. Under hypoxia, the number (A) and the volume (B) of RDsph were significantly higher than in normoxia. (A) $\mathrm{p}=0.021, \mathrm{n}=4$; (B) $\mathrm{p}=0.009, \mathrm{n}=3$. Scale bar, $100 \mu \mathrm{m}$. (C) Under hypoxia, the growth of RDsph was significantly higher than in normoxia condition. $\mathrm{p}=0.016, \mathrm{n}=4$. (D) Gene expression of OCT3/4, Nanog and SOX2 revealed an increase (not significant) under hypoxia condition compared to normoxia. $\mathrm{n}=6$.

survival. Although the clinical relevance of CSCs is yet to be proved in solid cancers, different anti-leukemic stem cell agents have already been used in ongoing clinical trials (29). Impressive research work has been done in this field, giving evidence that the CSCs population actually represents the fuel of the tumor and its eradication may be expected to have remarkable clinical perspectives. It has been shown that CSCs, like normal stem cells (30), are able to grow as free-floating spheroidal aggregates in non-adherent conditions, as initially observed in leukemias $(4,5)$ and subsequently in solid tumors. Thanks to this peculiarity, CSCs of brain and breast cancers, known as neurospheres and mammospheres, respectively, have been identified and are now subject of investigation for new targeted therapies $(8,9,31)$. Similarly, CSC-enriched sphere cultures have been established and characterised from other solid tumors (8-15). Despite these promising advancements, the identification of CSCs in sarcomas is still fraught with difficulties as a result of some intrinsic peculiarities of these neoplasms $(2,32,33)$, including the unclear pathogenesis (34) and the lack of a general consensus regarding the markers that define the putative mesenchymal progenitors $(35,36)$. Current data have been largely based on continuous cell lines (18-21) rather than on tissue specimens $(23,24)$. Indirect assays, such as the isolation of the side population, the ALDH activity $(25,26)$, and the expression of CD133 cell marker $(23,37)$ have been advocated as alternative tools to identify sarcoma CSCs, but their reliability as stemness indicators is still debated (33). Interestingly, CSCs from Ewing's sarcoma are involved in chemoresistance (38). The conclusive identification of the sarcoma CSC population and its role in the pathogenic process could have a remarkable health impact, especially for these tumors where conventional therapies are often unsuccessful. In our study, we analysed the efficiency of the sphere system assay for the isolation of CSC-enriched fractions of sarcomas. For this purpose, we collected a number of human fresh tissue biopsies, specifically 49 samples of bone and soft tissue sarcomas. After a culturing period that, interestingly, was shorter for samples derived from tumor relapses and for more aggressive neoplasms, we were disappointed that we succeeded in obtaining spheres only in a minority (10\%) of cases, an isolation efficiency that appears to be lower than that reported in other solid neoplasms (39). However, it has already been reported that experimental design variables, such as the tumor stage of origin, could influence the isolation 
efficacy (40). It is also possible that the culture conditions for mesenchymal tumors are different from those that have been originally defined as optimal for epithelial tumors. Another reason for such unsatisfactory yield could be that standard in vitro methods do not take into sufficient account some peculiar characteristics of tumor environment. For example, it is known that CSCs reside in a niche, both in the bone marrow and in soft tissues, where the oxygen tension is characteristically lower (3-4\%) than that used for standard culture conditions (21\%) (41) and that low oxygen levels are requested to maintain both normal and cancer stem cell phenotype $(42,43)$. It is also likely that within the tumor microenvironment the behaviour of CSCs, including proliferation and differentiation, is modulated by other stromal elements, such as immune cells and tumor-associated fibroblasts. The development of culture systems that more accurately recapitulates the complexity of sarcoma microenvironment could improve the ability to isolate, harvest and characterize sarcoma CSCs for further investigations. To assess the stemness of cells retrieved from sarcospheres, we analysed the expression of OCT3/4, Nanog and SOX2, all markers generally associated to CSC (44) and found a significantly higher mRNA level for all genes in CSCs as compared to parental cells. In a case of alveolar RMS and another of CS we were also able to demonstrate that cells retrieved from sarcospheres were able to form tumors after subcutaneous injection in athymic mice. Notably, the xenografts recapitulated the histologic pattern of the original tumors, both in terms of morphology and surface markers and, in the case of RMS, the transplanted cells originated from the sarcospheres were also carrying the same, distinctive $t(2 ; 13)$ translocation. To evaluate if a hypoxic culture environment could improve the sphere system method efficacy, we also analysed the effects of hypoxia on an RMS cell model, and found a strong increase in the number, volume and growth of the spheres. The control of oxygen levels also resulted in an increase in the expression of the stem cell markers here considered. Our study confirms that cells with CSC-like characteristics are present in human sarcoma tissue samples. The CSCs component can be enriched by the sphere system method and provide a reliable preclinical model that can be used for future studies aimed at investigating crucial aspects of sarcoma biology, such as resistance to treatments and relapse. It is likely that the reproducibility of the method for sarcoma CSCs may benefit from the adoption of culture conditions that take into account the peculiarities of the stem niche and the mutual interactions of CSCs and reactive elements within the tumor microenvironment.

\section{Acknowledgements}

The authors would like to thank Lucy Scioscia for the English revision of the manuscript. This study was supported by grant FIRB: RBAP10447J from the Italian Ministry of Education, Universities and Research.

\section{References}

1. Luis ÁM, Aguilar DP and Martín JA: Multidisciplinary management of soft tissue sarcomas. Clin Transl Oncol 12: 543-553, 2010.

2. Burningham Z, Hashibe M, Spector L and Schiffman JD: The epidemiology of sarcoma. Clin Sarcoma Res 2: 13-16, 2012.
3. Keedy VL: Treating metastatic soft-tissue or bone sarcomas potential role of ridaforolimus. Onco Targets Ther 5: 153-160, 2012.

4. Lapidot T, Sirard C, Vormoor J, et al: A cell initiating human acute myeloid leukaemia after transplantation into SCID mice. Nature 17: 645-648, 1994.

5. Bonnet D and Dick JE: Human acute myeloid leukemia is organized as a hierarchy that originates from a primitive hematopoietic cell. Nat Med 3: 730-737, 1997.

6. Reya T, Morrison SJ, Clarke MF and Weissman IL: Stem cells, cancer, and cancer stem cells. Nature 414: 105-111, 2001.

7. Jordan CT, Guzman ML and Noble M: Cancer stem cells. N Engl J Med 355: 1253-1261, 2006.

8. Al-Hajj M, Wicha MS, Benito-Hernandez A, Morrison SJ and Clarke MF: Prospective identification of tumorigenic breast cancer cells. Proc Natl Acad Sci USA 100: 3983-3988, 2003.

9. Singh SK, Clarke ID, Terasaki M, Bonn VE, Hawkins C, Squire J and Dirks PB: Identification of a cancer stem cell in human brain tumors. Cancer Res 63: 5821-5828, 2003.

10. Ricci-Vitiani L, Lombardi DG, Pilozzi E, Biffoni M, Todaro M, Peschle $C$ and De Maria R: Identification and expansion of human colon-cancer-initiating cells. Nature 445: 111-115, 2007.

11. Li C, Heidt DG, Dalerba P, et al: Identification of pancreatic cancer stem cells. Cancer Res 67: 1030-1037, 2007.

12. Schatton T, Murphy GF, Frank, NY, et al: Identification of cells initiating human melanomas. Nature 451: 345-349, 2008.

13. Zhang S, Balch C, Chan MW, et al: Identification and characterization of ovarian cancer-initiating cells from primary human tumors. Cancer Res 68: 4311-4320, 2008.

14. Lang Sh, Frame F and Collins A: Prostate cancer stem cells. J Pathol 217: 299-306, 2009.

15. Ponti D, Costa A, Zaffaroni N, et al: Isolation and in vitro propagation of tumorigenic breast cancer cells with stem/progenitor cell properties. Cancer Res 65: 5506-5511, 2005.

16. Deleyrolle LP, Ericksson G, Morrison BJ, et al: Determination of somatic and cancer stem cell self-renewing symmetric division rate using sphere assays. PLoS One 6: e15844, 2011.

17. Liu T, Cheng W, Lai D, Huang Y and Guo L: Characterization of primary ovarian cancer cells in different culture systems. Oncol Rep 23: 1277-1284, 2010.

18. Gibbs CP, Kukekov VG, Reith JD, et al: Stem-like cells in bone sarcomas: implications for tumorigenesis. Neoplasia 7: 967-976, 2005.

19. Fujii H, Honoki K, Tsujiuchi T, Kido A, Yoshitani K and Takakura Y: Sphere-forming stem-like cell populations with drug resistance in human sarcoma cell lines. Int J Oncol 34: 1381-1386, 2009.

20. Wang L, Park P and Lin CY: Characterization of stem cell attributes in human osteosarcoma cell lines. Cancer Biol Ther 8: 543-552, 2009.

21. Rainusso N, Man TK, Lau CC, et al: Identification and gene expression profiling of tumor-initiating cells isolated from human osteosarcoma cell lines in an orthotopic mouse model. Cancer Biol Ther 12: 278-287, 2011.

22. Basu-Roy U, Seo E, Ramanathapuram L, et al: Sox 2 maintains self renewal of tumor-initiating cells in osteosarcomas. Oncogene 31: 2270-2282, 2012

23. Suvà ML, Riggi $\mathrm{N}$, Stehle JC, et al: Identification of cancer stem cells in Ewing's sarcoma. Cancer Res 69: 1776-1781, 2009.

24. Sette G, Salvati V, Memeo L, et al: EGFR inhibition abrogates leiomyosarcoma cell chemoresistance through inactivation of survival pathways and impairment of CSC potential. PLoS One 7: e46891, 2012.

25. Murase M, Kano M, Tsukahara T, et al: Side population cells have the characteristics of cancer stem-like cells/cancer-initiating cells in bone sarcomas. Br J Cancer 101: 1425-1432, 2009.

26. Lohberger B, Rinner B, Stuendl N, et al: Aldehyde dehydrogenase 1, a potential marker for cancer stem cells in human sarcoma. PLoS One 7: e43664, 2012.

27. Heddleston JM, Li Z, Lathia JD, Bao S, Hjelmeland AB and Rich JN: Hypoxia inducible factors in cancer stem cells. Br J Cancer 102: 789-795, 2010.

28. Livak KJ and Schmittgen TD: Analysis of relative gene expression data using real-time quantitative PCR and the 2(-Delta Delta C(T)) method. Methods 25: 402-408, 2001.

29. Felipe Rico J, Hassane DC and Guzman ML: Acute myelogenous leukemia stem cells: from bench to bedside. Cancer Lett: Jun 17, 2012 (Epub ahead of print).

30. Reynolds BA and Weiss S: Generation of neurons and astrocytes from isolated cells of the adult mammalian central nervous system. Science 255: 1707-1710, 1992. 
31. Hallett RM, Kondratyev MK, Giacomelli AO, Nixon AM, Girgis-Gabardo A, Ilieva D and Hassell JA: Small molecule antagonists of the Wnt/ $\beta$-catenin signaling pathway target breast tumor-initiating cells in a Her2/Neu mouse model of breast cancer. PLoS One 7: e33976, 2012.

32. Gibbs CP Jr, Levings PP and Ghivizzani SC: Evidence for the osteosarcoma stem cell. Curr Orthop Pract 22: 322-326, 2011.

33. Trucco M and Loeb D: Sarcoma stem cells: do we know what we are looking for? Sarcoma 2012: 291705: May 9, 2012 (Epub ahead of print). doi: 10.1155/2012/291705.

34. Galli R, Borello U, Gritti A, et al: Skeletal myogenic potential of human and mouse neural stem cells. Nat Neurosci 3: 986-991, 2000.

35. Toguchida $\mathbf{J}$ and Nakayama T: Molecular genetics of sarcomas: applications to diagnoses and therapy. Cancer Sci 100: 1573-1580, 2009.

36. Tolar J, Nauta AJ, Osborn MJ, et al: Sarcoma derived from cultured mesenchymal stem cells. Stem Cells 25: 371-379, 2007.

37. Tirino V, Desiderio V, Paino F, et al: Human primary bone sarcomas contain $\mathrm{CD} 133^{+}$cancer stem cells displaying high tumorigenicity in vivo. FASEB J 25: 2022-2030, 2011.

38. Jiang X, Gwye Y, Russell D, et al: CD133 expression in chemoresistant Ewing sarcoma cells. BMC Cancer 10: 116-127, 2012.
39. Hemmati HD, Nakano I, Lazareff JA, Masterman-Smith M, Geschwind DH, Bronner-Fraser M and Kornblum HI: Cancerous stem cells can arise from pediatric brain tumors. Proc Natl Acad Sci USA 100: 15178-15183, 2003.

40. Gupta PB, Chaffer CL and Weinberg RA: Cancer stem cells: mirage or reality? Nat Med 5: 1010-1012, 2009.

41. Mohyeldin A, Garzón-Muvdi T and Quiñones-Hinojosa A: Oxygen in stem cell biology: a critical component of the stem cell niche. Cell Stem Cell 7: 150-161, 2010.

42. Rosová I, Dao M, Capoccia B, Link D and Nolta JA: Hypoxic preconditioning results in increased motility and improved therapeutic potential of human mesenchymal stem cells. Stem Cells 26: 2173-2182, 2008

43. McCord AM, Jamal M, Shankavaram UT, Lang FF, Camphausen K and Tofilon PJ: Physiologic oxygen concentration enhances the stem-like properties of $\mathrm{CD}_{133^{+}}$human glioblastoma cells in vitro. Mol Cancer Res 7: 489-497, 2009.

44. Okita K, Ichisaka T and Yamanaka S: Generation of germlinecompetent induced pluripotent stem cells. Nature 448: 313-317, 2008 . 